\title{
Evaluation of educators' performance—balancing various measures to improve practice
}

\author{
Guri Skedsmo $^{1,2} \cdot$ Stephan Gerhard Huber ${ }^{1}$
}

Published online: 14 June 2017

(C) Springer Science+Business Media, LLC 2017

Ample literature documents the importance of the quality of educators for effective student learning. In the editorial for the second issue of EAEA in 2016 (Huber and Skedsmo 2016), we pointed out that questions can be raised about the links between policy and research, and the extent to which policies regarding teacher evaluation consider empirical evidence when new models for teacher evaluations are promoted and implemented (cf. Gunter 2002). On the basis of their analysis of the evidence from research into teacher evaluation and the impact on school improvement, Hallinger et al. (2014) conclude that the policy logic supporting and driving teacher evaluation remains considerably stronger than the empirical evidence of positive results. Moreover, they argue that the literature on the new generation of teacher evaluation is characterised by overly optimistic interpretations of the underlying literature and a tendency to overlook important limitations of the research designs.

Methods to measure teacher quality and the systems of teacher performance assessment are diverse and depend on the national or local context. Santelices et al. (in this issue) refer to three main approaches observed in the literature: (1) teacher quality based on observable characteristics, (2) the assessment of classroom practices based on professional standards and (3) teacher effect estimates based on students' test scores. These assessment approaches have been used as part of initiatives that hold teachers accountable for students' learning, often without taking contextual variables into account. In the field of education, many of the methods used in performance assessment aim to combine the purposes of holding educators to account for students' learning outcomes and providing a basis for professional development. In this issue,

Guri Skedsmo

guri.skedsmo@ils.uio.no

$\bowtie$ Stephan Gerhard Huber stephan.huber@phzg.ch

1 Institute for the Management and Economics of Education, University of Teacher Education Zug, Zug, Switzerland

2 Department of Teacher Education and School Research, University of Oslo, Oslo, Norway 
several concerns are brought to the forefront, in particular the implementation in different contexts of teacher evaluation models that aim to provide a good measure for teaching quality. Further, the role of principals, their competencies to evaluate teachers' practice and the exercise of learning-centred leadership are investigated. Finally, implications for policy, practice and further research are elaborated.

\section{Articles in this issue of EAEA 2/2017}

In their article about teacher evaluation in Chile, Santelices, Valencia, Gonzales and Taut report on a study that aims to contribute to the discussion on how to assess and improve teacher performance. After the introduction of a general voucher system in 1981, primary and secondary education in Chile comprises three types of schools: private and private subsidised, which account for more than half of the student enrolment and public schools (42\% of student enrolment). Attendance at the different school types is highly related to income level, and research has shown that student results differ significantly by socio-economic status and the type of school attended. Decentralisation of the responsibility for schools to the municipal authorities has also led to increased segregation. During the last two decades, several policy initiatives have been introduced to improve the performance of teachers, and in 2003, standardised procedures for teacher evaluation were implemented for teachers in public schools. These procedures include four instruments: (1) a structured portfolio comprising a written part and a videotaped lesson, (2) a peer interview, (3) a supervisor's assessment and (4) self-assessment. In the article, the authors report on the results from a study that empirically examines the relationship between two measures of teacher quality: one based on professional standards and a second one using teacher value-added estimates. Particular focus is directed towards the extent to which teacher observable characteristics, such as teacher training variables, are associated with better performance on either of these measures. Moreover, the authors investigate whether either of these two assessments is able to effectively measure teacher quality isolated from the influence of the context where teachers work, in this case, understood as the characteristics of the schools and districts that may influence student learning but are not under the direct control of the teachers. Using data from national databases and standardised local assessments, the authors apply hierarchical linear models and find that there is only a limited relationship between the two measures of teacher quality. Context, on both the school and municipal levels, plays an important role not only in the teacher effect measure, but also in the standard-based measures. This means that teacher performance is measured either by VA estimates or by a standard-based measure, and as such, it is related to factors outside of the teacher's control. As a consequence, it is uncertain that these two approaches provide a good measure of teacher performance, and the authors suggest emphasising alternative ways, such as video observations, which incorporate the context by focusing more on the interaction between students and teachers and thereby strengthen formative aspects and professional development.

In the second article in this issue, Briggs and Dadey report on an analysis of how principals in Georgia (USA) evaluated their teachers. Georgia was one out of 19 states that received funding from a competitive federal grant called 'Race to the Top' (RTTT), which was launched in 2009. The intended purpose of the grant was to spur and reward 
innovations and reforms at the district and state levels in $\mathrm{K}-12$ education with an emphasis on implementing performance-based evaluations for teachers that relied on multiple measures. In Georgia, a system called 'Teacher Keys Effectiveness System' (TKES) was launched, which included indicators of student growth (as measured by students' growth percentiles) and ratings according to the Teacher Assessment on Performance Standards (TAPS), which in most schools are completed by the school's principal or the assistant principal. In addition, the authors conducted a survey wherein they aimed to capture the principals' direct and indirect holistic judgments of their teachers. In their analysis, they find a positive association between these indirect and direct holistic principal judgments, student growth and the analytic scores of teachers from observations of classroom practice that most of the principals had themselves conducted. However, their results also indicate that principals' holistic judgments are more strongly influenced by their perspective on a teacher's classroom practices and other observable contributions to their schools than they are by data that indicates a teacher's influence on student growth. The authors found that this was particularly evident in the principals' rationale for selecting teachers as most or least successful at increasing student achievement (and especially in the latter case). With respect to the multiple measures of teacher effectiveness that are required in RTTT-funded procedures, these findings are important with respect to balancing holistic and analytical judgments as well as measures of growth in student achievement.

Teacher evaluation models under RTTT policies are also under scrutiny in the third article in this issue. Lavigne and Chamberlain investigate school leaders' perceptions and practices of the teacher evaluation model implemented in Illinois (USA). Illinois was also among the 19 states that obtained federal RTTT funding to develop and implement teacher evaluation. According to the authors, prior to receiving the funds, Illinois had passed the Performance Evaluation Reform Act (PERA), which requires student achievement growth to be a significant factor in evaluations, all teachers to be evaluated using a four-category rating system and evaluators to have completed a training programme in order to be certified to evaluate teachers. The study draws from the survey data of $606 \mathrm{~K}-$ 12 school leaders in the USA in a state implementing a new teacher evaluation model. Their findings show first that school leaders spent substantial time on teacher evaluation. While some of them felt that this was a good investment of time (e.g., rich conversations with teachers), increasing the ability for evaluations to improve instruction, most of them perceived the time demands as a cost (e.g., spending longer hours on the job, delegating more tasks to others). Second, the authors find that school leaders feel confident in their ability to conduct observations and provide feedback to teachers. In contrast, school leaders seem to struggle with using of student achievement data to evaluate teachers. Based on their study, the authors point out several implications, for instance, that school leaders need resources to build capacity, particularly in accommodating the new time demands of teacher evaluation. Moreover, they advocate professional development that addresses the use and value of student achievement if this measure continues to be a substantial component in teacher evaluation models.

The last article by Minor, Porter, Murphy, Goldring and Elliott addresses the assessment of school leaders. The Vanderbilt Assessment for Leadership in Education (VAL-ED) is a 360-degree evaluation tool that includes ratings from the principal themselves, their supervisors and teachers. Given the accountability and effective schools movement, the authors argue that it is vitally important to have a high- 
quality measure of learning-centred leadership behaviours. To adhere to testing standards, VAL-ED has been subjected to rigorous investigation of its psychometric properties (e.g., reliability and validity on a national representative sample of schools in the USA) and was developed to address the weakness of other principal evaluation systems by being grounded in leadership research and school improvement, aligned to the Interstate School Leaders Licensure Consortium (ISLLC) standards. In this article, the authors report on results from assessing the test-retest reliability of VAL-ED for a sample of seven school districts as part of multiple validity and reliability assessments based on various samples of real users of VAL-ED. In other words, rather than recruiting schools for the express purpose of research and asking them to take VALED, the real user studies recruited schools that are already using VAL-ED for their own purposes. The results show that VAL-ED is a valid and reliable principal evaluation tool for those samples of real users examined as well as in research sites for the nationally representative sample in the USA.

\section{Reflections and questions for further discussion}

Three articles raise questions with respect to the functions and the balance of different measures of teacher evaluation included in models implemented at the national and state level. Often, a standardised measure of student achievement, or even growth of student achievement, is evaluated against standardised procedures for teaching observations, where teachers receive scores on various areas that are weighted and put into a sum score. While the articles by Santelices et al. and Briggs and Dadey examine different measures, Lavigne and Chamberlain also delve into the implications with regard to the work conditions and practices of school principals. They emphasise how principals seem to have difficulties using the measures to develop the practice as part of their learning-centred leadership. While the observations of teachers have traditionally been an integral part of their professional practice, the use of growth measures may be perceived as an external knowledge source. Possible implications may be that principals as well as teachers need to develop their capacity to make sense of such information and apply it to improve their practice. In this case, it would be interesting to explore how Minor et al. defined and operationalised learning-centred leadership and whether they have found similar challenges in assessing principals' competencies. At the same time, questions can be raised with regard to whether such information has been designed for formative purposes and whether it can be used by principals to promote reflective and inquiry-based approaches to develop teaching practices.

\section{References}

Gunter, H. M. (2002). Teacher appraisal 1988-1998: a case study. School Leadership and Management, 22(1), 61-72.

Hallinger, P., Heck, R., \& Murphy, J. (2014). Teacher evaluation and school improvement: an analysis of the evidence. Educational Assessment, Evaluation and Accountability, 26(1), 5-28.

Huber, S. G., \& Skedsmo, G. (2016). Teacher evaluation - accountability and improving teaching practices. Educational Assessment, Evaluation and Accountability, 28(2), 105-109. doi:10.1007/s11092-016-9241-1. 